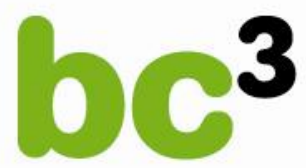

BASQUE CENTRE

FOR CLIMATE CHANGE

Klima Aldaketa Ikergai

\title{
Effects of Carbon Dioxide Capture and Storage in Germany on European Electricity Exchange and Welfare
}

\author{
Dirk Rübbelke \\ Stefan Vögele
}

June 2012

BC3 WORKING PAPER SERIES 
The Basque Centre for Climate Change (BC3) is a Research Centre based in the Basque Country, which aims at contributing to long-term research on the causes and consequences of Climate Change in order to foster the creation of knowledge in this multidisciplinary science.

The BC3 promotes a highly-qualified team of researchers with the primary objective of achieving excellence in research, training and dissemination. The Scientific Plan of BC3 is led by the Scientific Director, Prof. Anil Markandya.

The core research avenues are:

- $\quad$ Adaptation to and the impacts of climate change

- $\quad$ Measures to mitigate the amount of climate change experienced

- International Dimensions of Climate Policy

- Developing and supporting research that informs climate policy in the Basque Country

See www.bc3research.org for further details.

The BC3 Working Paper Series is available on the internet at http://www.bc3research.org/working_papers/view.html

Enquiries (Regarding the BC3 Working Paper Series):

Roger Fouquet

Email: roger.fouquet@bc3research.org

The opinions expressed in this working paper do not necessarily reflect the position of Basque Centre for Climate Change (BC3) as a whole.

Note: If printed, please remember to print on both sides. Also, perhaps try two pages on one side. 


\title{
Effects of Carbon Dioxide Capture and Storage in Germany on European Electricity Exchange and Welfare
}

\author{
Dirk Rübbelke*,** and Stefan Vögele ***
}

June 2012

In the course of European efforts to mitigate global warming, the application of carbon dioxide capture and storage (CCS) technologies is discussed as a potential option. Some political opposition was raised - inter alia - by uncertainties about the effective cost of such technologies. Because of the cost structure of CCS power plants with high 'flat' investment cost and - in case of high carbon allowance prices - comparable low variable cost, the application of CCS will induce a merit-order effect causing a decline in electricity prices on the spot market. On the one hand, the reduction of electricity supply cost raises suppliers' rents, while the decline of electricity prices augments consumers' surpluses. These positive welfare effects tend to mitigate political opposition against CCS. On the other hand, the merit-order effect reduces electricity suppliers' revenues as the electricity prices decline. This mitigates their scope for additional investments in CCS capacity. In this study, we focus on the influence of CCS in Germany on electricity supplier and consumer surpluses and associated impacts on the scope for investments in additional CCS capacity. By means of the applied model of electricity markets, influences on European electricity exchange and welfare levels are investigated.

Keywords: Carbon dioxide capture and storage (CCS), merit-order effect, redistribution of wealth

JEL Classifications: Q40, Q54, F18

Cite as: Rübbelke, D. and Vögele, S. (2012), Effects of Carbon Dioxide Capture and Storage in Germany on European Electricity Exchange and Welfare. BC3 Working Paper Series 2012-05. Basque Centre for Climate Change (BC3). Bilbao, Spain.

* Basque Centre for Climate Change (BC3), Alameda Urquijo, 4-4, 48008, Bilbao, Spain, email: dirk.ruebbelke@bc3research.org

** IKERBASQUE, Basque Foundation for Science, 48011, Bilbao, Spain

*** Forschungszentrum Jülich $\mathrm{GmbH}$, Institute of Energy and Climate Research - Systems Analysis and Technology Evaluation (IEK-STE), 52425 Jülich, Germany, email: s.voegele@fzjuelich.de 


\section{Introduction}

Carbon dioxide capture and storage (CCS) is seen as a major option to mitigate global greenhouse gas emissions. The IEA (2011b) considers it as a key abatement option in the 450-ppm scenario that is expected to be largely consistent with meeting the international ' $2{ }^{\circ} \mathrm{C}$-target'. ${ }^{1}$ Though, due to immaturity of CCS technologies, associated risks (unintended leakage or accidental release of carbon dioxide) and negative influence on power plant efficiencies, this technology is controversially discussed. Yet, technological immaturity can be overcome by learning processes in association with the running of demonstration plants and this learning will also help to reduce technological risks. ${ }^{2}$ Energy losses (energy penalty) due to the use of CCS are - in turn not seen as "a major restriction to an extensive application of coal-fired CCS technologies" as there is "abundant availability of coal and potentially also hydrates" (Edenhofer et al. 2011: 88). A fourth problem might however be more serious, which is the restriction of a limited availability of suitable geological disposal opportunities. This is a major constraint for the pursuit of this climate protection path such that CCS is largely seen as a transitional technology which might enable a 50-year transition towards renewable energy and away from fossil fuels (Haszeldine 2009: 1647).

Yet, for CCS to take this transitional-technology role, the 'crucial question' is at what costs CCS technologies can be induced by climate policy (Edenhofer et al. 2011: 89). Viebahn et al. (2007) stress that depending on the growth rates and the market development, the 'mitigation' option in the shape of renewable energy technologies "could develop faster and could be in the long term cheaper than CCS based plants". ${ }^{3}$ As Oltra et al. (2010: 698) remark, opposition of non-governmental organizations, experts and other industries to CCS may cause a decreasing social acceptance of these

\footnotetext{
${ }^{1}$ Yet, Stauffer et al. (2011: 8597) point out that „CCS technology must be deployed at a massive scale to have a meaningful impact on reducing industrial $\mathrm{CO}_{2}$ emissions to the atmosphere."

${ }^{2}$ However, uncertainty about large-scale implementation will still remain.

${ }^{3}$ However, Hoel and Jensen (2010) describe circumstances under which the support of the development of CCS technologies is preferable to supporting renewable energy technologies.
} 
technologies. ${ }^{4}$ And rising opposition - in turn - might increase the costs in connection with CCS use. And Praetorius and Schumacher (2009: 5085) point out that environmentalists and renewable-energy lobbyists fear the competition between CCS and renewable-energy technologies for R\&D funds and are worried that CCS might raise attractiveness of investments in large centralized power plants which tend to reinforce present supply structures with adverse effects on energy saving efforts, decentralized renewable energies and combined heat and power generation. However, in a survey three-quarters of the participating European energy stakeholders were of the opinion that CCS is 'definitely' or 'probably necessary' to achieve deep reductions in $\mathrm{CO}_{2}$ emissions between 2006 and 2050 in their home country (Shackley et al. 2007). And after the Fukushima catastrophe negatively influencing the attitude towards nuclear energy technology, $\mathrm{CCS}$ as a nearly $\mathrm{CO}_{2}$-free technique tends to become more attractive. $^{5}$

There are several studies ascertaining the effectiveness of CCS in mitigating $\mathrm{CO}_{2}$ emissions and the associated cost. According to the IPCC (2005: 4), about $85-95 \%$ of the carbon dioxide in a plant can be captured by available CCS technologies. As a lower bound for the energy penalty for post-combustion CCS from pulverized-coal fired power plants, House et al. (2009) ascertain a level of $\sim 11 \%$, but assess that $\sim 29 \%$ would be a decent target value. The IPCC (2005: 4) estimates that the ranges for losses of energy compared to plants not equipped with CCS technology is $24-40 \%$ for pulverized coal plants, $11-22 \%$ for natural gas combined cycle plants and $14-25 \%$ for integrated gasification combined cycle plants. According to the IEA (2009: 23), application of CCS for large coal-fired power plants will represent the lowest cost opportunity within the power sector at around USD 35 to USD $50 / \mathrm{tCO}_{2}$ avoided while capture from gas-fired plants will involve cost within the range of USD 53 to USD $66 / \mathrm{tCO}_{2}$ avoided.

\footnotetext{
${ }^{4}$ As Hake et al. (2009: 3923) put it, "On the one hand, CCS can be perceived as a solution for the climatefriendly use of coal. [...] On the other hand, CCS itself may suffer from the negative image of coal in certain sections of the population."

${ }^{5}$ Subsequently, we disregard the option of combining bioenergy with CCS which would even constitute an option removing $\mathrm{CO}_{2}$ emissions from the atmosphere (see, e.g., Azar et al. 2006 and Ricci 2012 for this option).
} 
Application of CCS and related cost will not only provoke allocative shifts by changing the level and structure of climate change mitigation activity, but it will also have distributional effects. Recently, Lüken et al. (2011) investigated distributive impacts of climate change mitigation policy among different world regions taking into account the influence of CCS application also. They find that the unavailability of CCS will raise wealth redistributions among world regions (Lüken et al. 2011: 6037).

We are also interested in the distributional consequences of CCS use, but in contrast to the study by Lüken et al. (2011), we employ an electricity model focusing on panEuropean distributional consequences of CCS application in Germany. We ascertain impacts on international electricity exchanges in Europe as well as on consumer and producer surpluses by using this model in combination with a merit-order approach ${ }^{6}$. While positive effects on consumer and supplier surpluses are important for weakening political opposition to CCS, a rise in suppliers' revenues would also be a crucial factor in gaining sufficient funding for additional investments in CCS capacity.

In detail, we proceed as follows. In Section 2, we present approach and model employed for our analysis, and we introduce the scenarios we investigate. Section 3 gathers the results of our model and a discussion of these. Section 4 concludes.

\section{Methodology and Scenarios}

\subsection{Producer and Consumer Surplus}

In our analysis of potential CCS development paths, we employ a producer surplus approach measuring changes in electricity producers' profits. This approach has - in comparison to standard comparative cost methods - the advantage that it captures both changes in prices and in electricity sales. This is much alike fundamental models of power markets, but our approach allows for a more explicit consideration of the rents of consumers of electricity also.

\footnotetext{
${ }^{6}$ See Sensfuß, Ragwitz and Genoese (2008) and Schaber, Steinke and Hamacher (2012) for examples of studies using merit-order approaches.
} 
Let us regard the producer surplus and its changes for illustrative purposes in a stylized example. In Figure 1, we assume that a linear electricity supply curve $c_{A}(e)$ drops due to an exogenous change in generation costs per unit of electricity e and the new curve is now depicted by $c_{B}(e)$. Given the linear energy demand function as displayed in Figure 1 , the initial market equilibrium is determined by the intersection of this demand function and the initial supply curve $c_{A}(e)$ in $A$. After the exogenous cost decrease, the new equilibrium is at $B$. As can be observed, the market price per unit of e drops from $p_{A}$ to $p_{B}$.

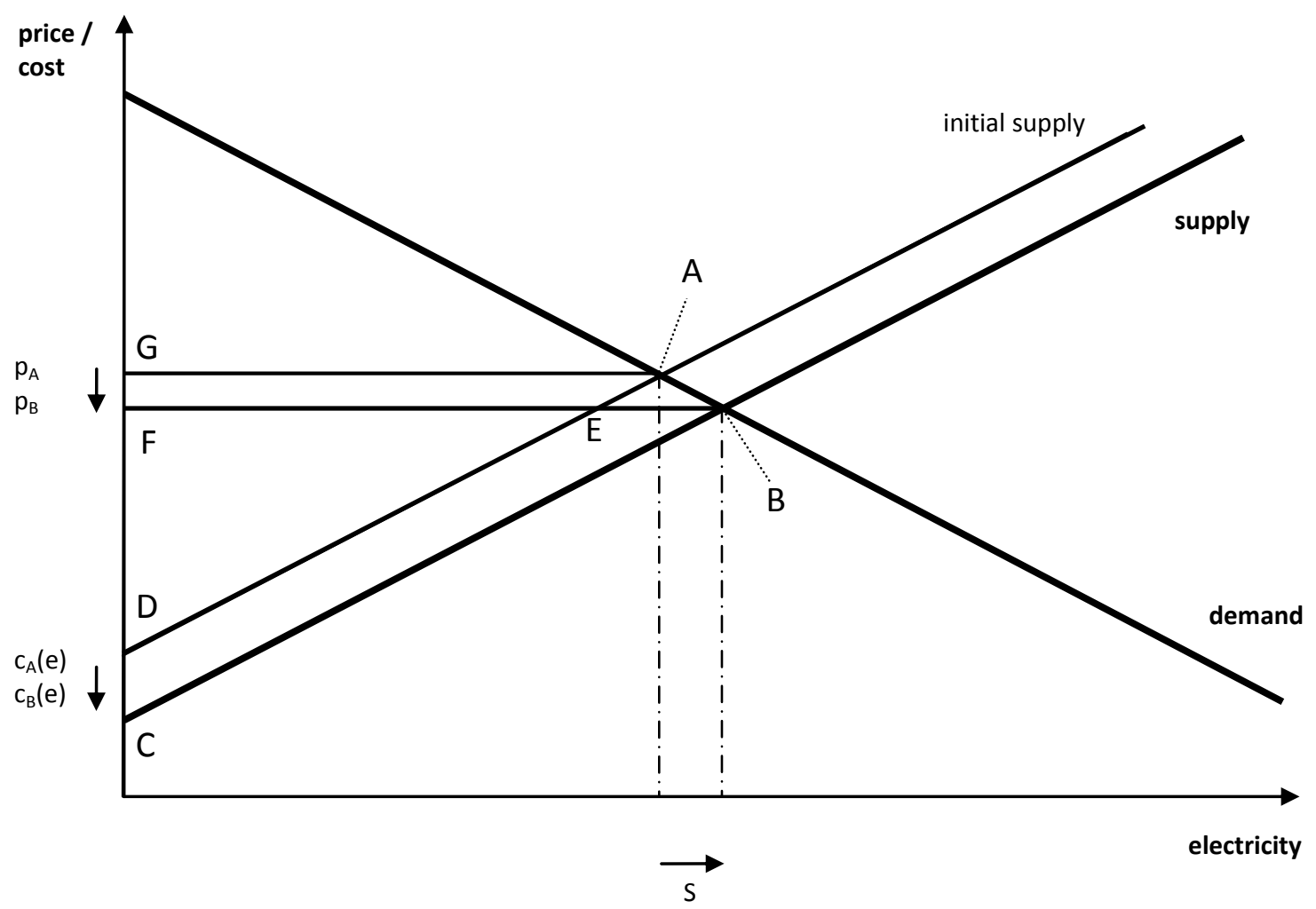

Figure 1: Change in Surpluses and the Market Equilibrium Induced by a Cost Decline on the Supply Side.

The suppliers obtain additional profits due to the decrease in the cost of supplying energy and the expansion of sales by the amount $\mathrm{S}$. These additional rents are depicted by the trapezium BCDE minus trapezium AEFG. The gains from declining cost and rising 
sales are diminished by the falling market price for electricity. Yet, net gains remain positive.

The consumers also benefit as the market price falls and the electricity consumption level increases. Consumer rents rise by the trapezium ABFG.

A cost decline could be induced on the electricity market by the application of technologies reducing carbon emissions. Due to the mitigation of emissions, lower cost for meeting emission caps and for related trading arise for electricity producers. One way to obtain such carbon emission mitigation and potentially a cost-saving effect is the application of CCS.

Yet, electricity is generated by different technologies and by using different inputs. CCS is not applicable to all of them and cost of CCS application - where possible - differs among technologies. Therefore, the heterogeneity of power generation plants has to be taken into account in the subsequent analysis.

\subsection{Description of the EU-electricity model}

\subsubsection{Methodology}

To assess the impacts of a use of CCS in Germany on electricity production, electricity prices and electricity exchanges we use a cost optimization approach. The objective function $Z_{t}$ of the model is depicted in the following cost minimization problem:

$$
\min Z_{t}=\sum_{n} \sum_{i} c_{i} \cdot s_{i, n, t} \cdot X_{i, n}+\sum_{n} \sum_{m} c_{l} i m p_{n, m, t}
$$

with

$t: \quad$ index for time [-]

$n, m: \quad$ index for the country

$i$ : $\quad$ index for power plant type

$c_{i}$ : $\quad$ operating cost of power plants of type $i$ [Euro/MWh]

$S_{i, n, t} \quad \quad$ average hourly utilization of power plants of type $i$ in country $n$, whereas $0 \leq s_{i, n} \leq 1[-]$

$X_{i, n}: \quad$ installed capacity of power plants of type $i$ in country $n$ [MW] 
$c_{l}: \quad$ costs for transferring electricity from one country to another one [Euro/MWh]

$\operatorname{imp}_{n, m, t}: \quad$ net-imports of electricity of country $n$ from country $m$ [Euro/MWh]

At each point in time electricity supply has to meet electricity demand whereas electricity can be supplied either by using domestic power plants or by importing electricity from a foreign country. This is taken into account by adding the following constraint:

$$
\sum_{i} s_{i, n, t} \cdot X_{i, n}+\sum_{m} i m p_{n, m, t} \geq d_{n, t} \quad \forall n
$$

$d_{n, t}$ : Electricity demand in country $n$ at time $t$.

Regarding the imports we take prevailing transfer constraints into account:

$$
i m p_{n, m, t} \leq N T C_{n, m} \quad \forall(n, m)
$$

with

$N T C_{n, m}$ : net transfer capacities.

The cost optimization approach has been implemented in GAMS with 1 hour as time resolution.

\subsubsection{Data}

Usually it is expected that CCS will not be commercially available in the power plant sector before 2020. In our study we thus chose 2030 as the starting point because until then it will be more likely that a high number of coal power plants will be equipped with CCS.

Information on power plants which will be installed in 2030 in Europe is extracted from EURELECTRIC (2010). EURELECTRIC expects an increase in the installed capacity by $33 \%$. The share of coal in the total installed capacity will decrease significantly whereas the share of wind and PV will increase. Also, the share of gas fired power plants will rise: Gas fired power plants will be used to satisfy augmentations in electricity demand in general as well as backup capacity for the wind and PV power plants. 
Based on data of grid operators and the "European Network of Transmission System Operators for Electricity" (ENTSO-E) we calculate each power plant type specific availability rates on an hourly level. Beside non-usability (e.g. because of limitations in solar radiation or insufficient wind) information on outage rates, need for maintenances and need for system service reserve are taken into account (ENTSO-E 2011a, ENTSO-E 2011b). Data of ENTSO-E is also used to assess the transnational electricity transfer.

Beside information on the different types of power plants which will be available in different countries, EURELECTRIC also provides information which helps to assess the vintage structure of the power plant stock. We use this information to draw inferences on power plant efficiencies and calculate power plant specific production cost by taking expected changes in fuel prices into account (IEA 2011c, EUELECTRIC 2010). Availability and non-availability periods of renewables power plants (REG) are taken into account by using data of grid operators (EEX 2011a, 2011b).

Three different types of CCS - techniques are currently favored:

- post-combustion with $\mathrm{CO}_{2}$ removal from flue gases by means of solvents (and thus captured after combustion),

- oxy-fuel combustion with burning coal with pure oxygen and

- $\quad$ pre-combustion with carbon removal from the energy carrier prior to the combustion process.

The three techniques differ in their technological proximity to existing power plants and in their cost (IEA 2011a, ZEP 2011). In this study we focus our analysis on postcombustion which seems to be the one which will become mature for the market first. In accordance with ZEP, we assume that greenfield coal fired power plants will have efficiency losses of $8 \%$ points compared to a conventional coal fired power plant while retrofitted power plants will face efficiency losses up to $12 \%$ points (ZEP 2011). The cost for $\mathrm{CO}_{2}$ transport and storage are assessed in our study with $5 \mathrm{Euro} / \mathrm{t} \mathrm{CO}_{2}$.

Changes in the electricity supply structure could have an impact on electricity prices and therefore on electricity demand. Regarding price impacts on the demand for electricity, it is important to distinguish between electricity prices at the spot market 
and end-user prices. Usually the end-user prices are 3-4 times higher than the electricity prices at the spot market because they include distribution cost and energy taxes and value added tax in addition. Thus, changes in the spot market prices have only small impacts on the end-user prices and therefore, do not induce significant immediate changes in the overall electricity demand (ENTSO-E 2011c). Taking this into account and that our study focuses on short-term impacts, we assume a price elasticity of 0 for the demand of electricity.

\subsubsection{Scenario Specification}

The scenarios we selected to assess the impact of CCS on the electricity supply system in Europe can be subdivided in three categories (for an overview see Table 1):

- Reference-scenarios: The reference scenarios are based on the assumption that CCS will not be commercially available in 2030. Therefore, none of the hard coal and lignite power plants will use this technology. To take uncertainties on the prices for $\mathrm{CO}_{2}$ allowances into account, we analyze different $\mathrm{CO}_{2}$-price scenarios. In the REF-20 we assume that the price for $\mathrm{CO}_{2}$ will increase to 20 Euro/t CO $\mathrm{CO}_{2}$, in the REF-30 to 30 Euro/t CO 2 and in the REF-40 to $40 \mathrm{Euro} / \mathrm{t} \mathrm{CO}_{2}$. In addition to the different $\mathrm{CO}_{2}$-price reference scenarios, two scenarios with modifications in the assumed installed wind and PV capacity in Germany are analyzed. In the first of these scenarios, we assume an additional increase in the installed wind power capacity by $10 \mathrm{GW}$ and in the PV capacity by $20 \mathrm{GW}$ (+ 10 GW Gas as backup capacity). In the second one, we postulate that the rise in the installed wind and PV capacities goes along with a decrease in the installed coal capacity by $10 \mathrm{GW}$.

- CCS-scenarios: In these scenarios we assume that new coal power plants have to be equipped with CCS in Germany. In addition, we postulate that older coal power plants in Germany are retrofitted with CCS techniques. All in all, in these scenarios hard coal-fired power plants with a capacity of $14.6 \mathrm{GW}$ and lignitefired power plants with a capacity of $13.7 \mathrm{GW}$ are equipped with CCS, and $67 \%$ of these power plants are retrofitted ones. In the CCS-scenarios we analyze the 
effects in the case of $\mathrm{CO}_{2}$-prices of 20 Euro/t, 30 Euro/t and 40 Euro/t $\mathrm{CO}_{2}$, respectively.

- REG-CCS-scenarios: These scenarios are used to demonstrate the effects of changes in installed REG-capacity on the use of CCS. In the REF30+REG and REF30red-REF we analyzed how electricity prices and producer rents will look like when we face different combinations of installed REG and CCS capacities.

Table 1: Overview of Scenarios

\begin{tabular}{|c|c|}
\hline Scenario & Description \\
\hline Reference & Situation 2030 \\
\hline “REF20“ & Price of $\mathrm{CO}_{2}$ allowances: 20 Euro/t $\mathrm{CO}_{2}$ \\
\hline “REF30“ & Price of $\mathrm{CO}_{2}$ allowances: 30 Euro/t $\mathrm{CO}_{2}$ \\
\hline “REF40“ & Price of $\mathrm{CO}_{2}$ allowances: 40 Euro/t $\mathrm{CO}_{2}$ \\
\hline "REF30+REG" & $\begin{array}{l}\text { REF30 with increase in the installed wind power capacity by } 10 \mathrm{GW} \\
\text { and in the PV capacity by } 20 \mathrm{GW}(+10 \mathrm{GW} \text { gas as backup capacity) }\end{array}$ \\
\hline "REF30red+REG" & $\begin{array}{l}\text { REF30 with reduced coal capacity (- } 10 \mathrm{GW}) \text { and increase in the } \\
\text { installed wind power capacity by } 10 \mathrm{GW} \text { and in the PV capacity by } 20 \\
\text { GW (+ } 10 \mathrm{GW} \text { gas as backup capacity) }\end{array}$ \\
\hline CCS & $\begin{array}{l}67 \% \text { of the installed hard coal and lignite power plants equipped with } \\
\text { CCS }\end{array}$ \\
\hline "CCS20" & Price of $\mathrm{CO}_{2}$ allowances: 20 Euro/t $\mathrm{CO}_{2}$ \\
\hline "CCS30" & Price of $\mathrm{CO}_{2}$ allowances: 30 Euro/t $\mathrm{CO}_{2}$ \\
\hline "CCS40“ & Price of $\mathrm{CO}_{2}$ allowances: 40 Euro/t $\mathrm{CO}_{2}$ \\
\hline \multicolumn{2}{|l|}{ REG-CCS } \\
\hline "CCS30+REG" & $\begin{array}{l}\text { CCS30 with increase in the installed wind power capacity by } 10 \mathrm{GW} \\
\text { and in the PV capacity by } 20 \mathrm{GW}(+10 \mathrm{GW} \text { gas as backup capacity) }\end{array}$ \\
\hline "CCSred30+REG" & $\begin{array}{l}\text { CCS30 with reduced CCS capacity (only } 18 \mathrm{GW} \text { instead of } 28 \mathrm{GW} \text { ), } \\
\text { increase in the installed wind power capacity by } 10 \mathrm{GW} \text { and in the } \\
\text { PV capacity by } 20 \mathrm{GW} \text { (+ } 10 \mathrm{GW} \text { gas as backup capacity) }\end{array}$ \\
\hline
\end{tabular}

Source: IEK-STE 2012 


\section{Results and Discussion}

In the event of increasing prices for $\mathrm{CO}_{2}$, the short-term production costs (costs without capital and other kinds of fixed costs) of CCS power plants tend to become lower than those of comparable conventional power plants. One example for the impacts of changes in the production costs on the distribution of the maximum production costs (which determines in a perfect market the price of electricity on the spot-market) is presented in Figure 2. This figure shows results of the REF30 and CCS30 scenarios calculated for Germany. It displays that if CCS power plants are used, then in half of the time the electricity price will be lower than in the case without CCS plants because of the lower electricity production costs of CCS power plants.

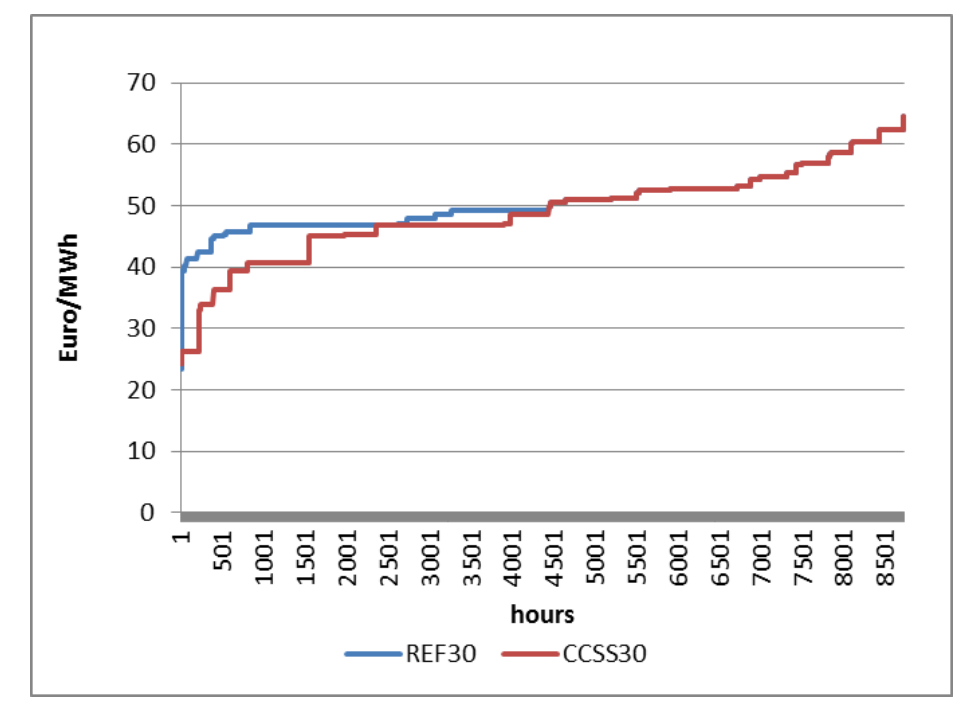

Source: Own calculations

Figure 2: Distribution of Maximum Production Costs During a Year.

In the CCS30-scenario the average electricity price is $3.7 \%$ lower than in the REF30scenario. With higher $\mathrm{CO}_{2}$-prices the price gap between CCS- and REF-scenario increases: In the CCS40 scenario the average electricity price is $6.4 \%$ lower than in the corresponding "Reference"-scenario (Table 2).

Lower electricity prices result in lower demand for electricity imports because it becomes cheaper to use domestic CCS-lignite-power plants than to import electricity produced by nuclear or hard coal-fired power plants. Consequently, Germany will import less electricity produced in nuclear power plants sited in France and Belgium as 
well as less electricity from coal power plants located, e.g. in Poland. Figure 3 shows the effect on electricity generation using the examples of REF30 and CC30. Comparing REF30 and CCS30, the use of CCS in Germany will result in an increase in the electricity production in Germany by $1.8 \%$.

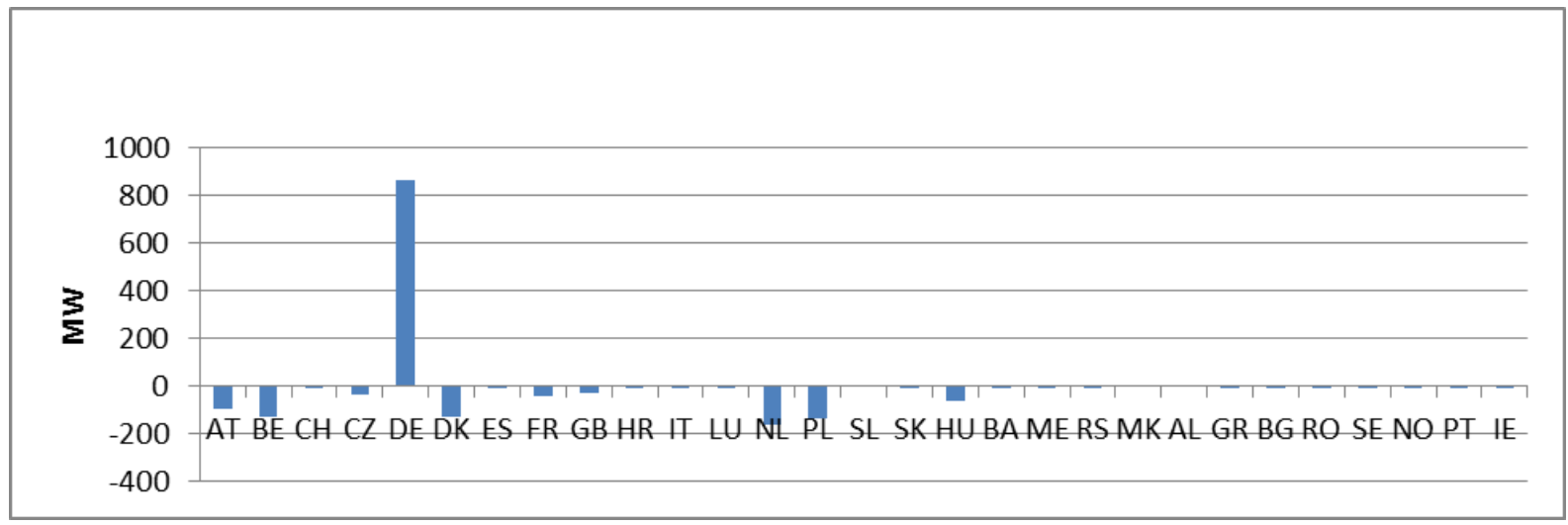

Source: Own calculations

Figure 3: Changes in Production (annual average).

Besides changes in the production levels and decreases in electricity prices, also the producer surplus is influenced by the shifts of the slope of the merit-order curve. Figure 4 shows the scenario specific merit-order curves for Germany calculated by using information on average utilization of the power plant techniques.

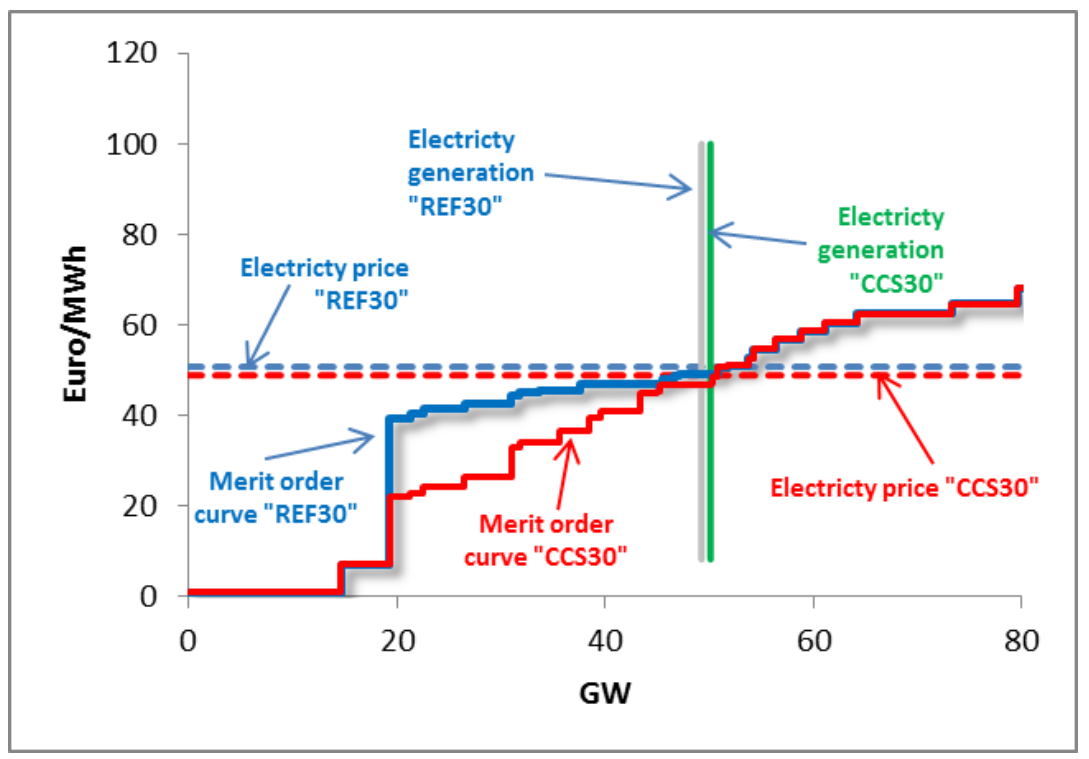

Source: Own calculations

Figure 4: Germany: Scenario Specific Merit-Order Curves (Yearly Average). 
As mentioned above the producer surplus is reflected by the area between electricity price and merit-order curve. In Germany the producer surplus will increase significantly in the scenario "CCS30" despite the decrease in electricity prices (Figure 5). In this scenario the additional producer surplus sums up to 1934 Mio. Euro.

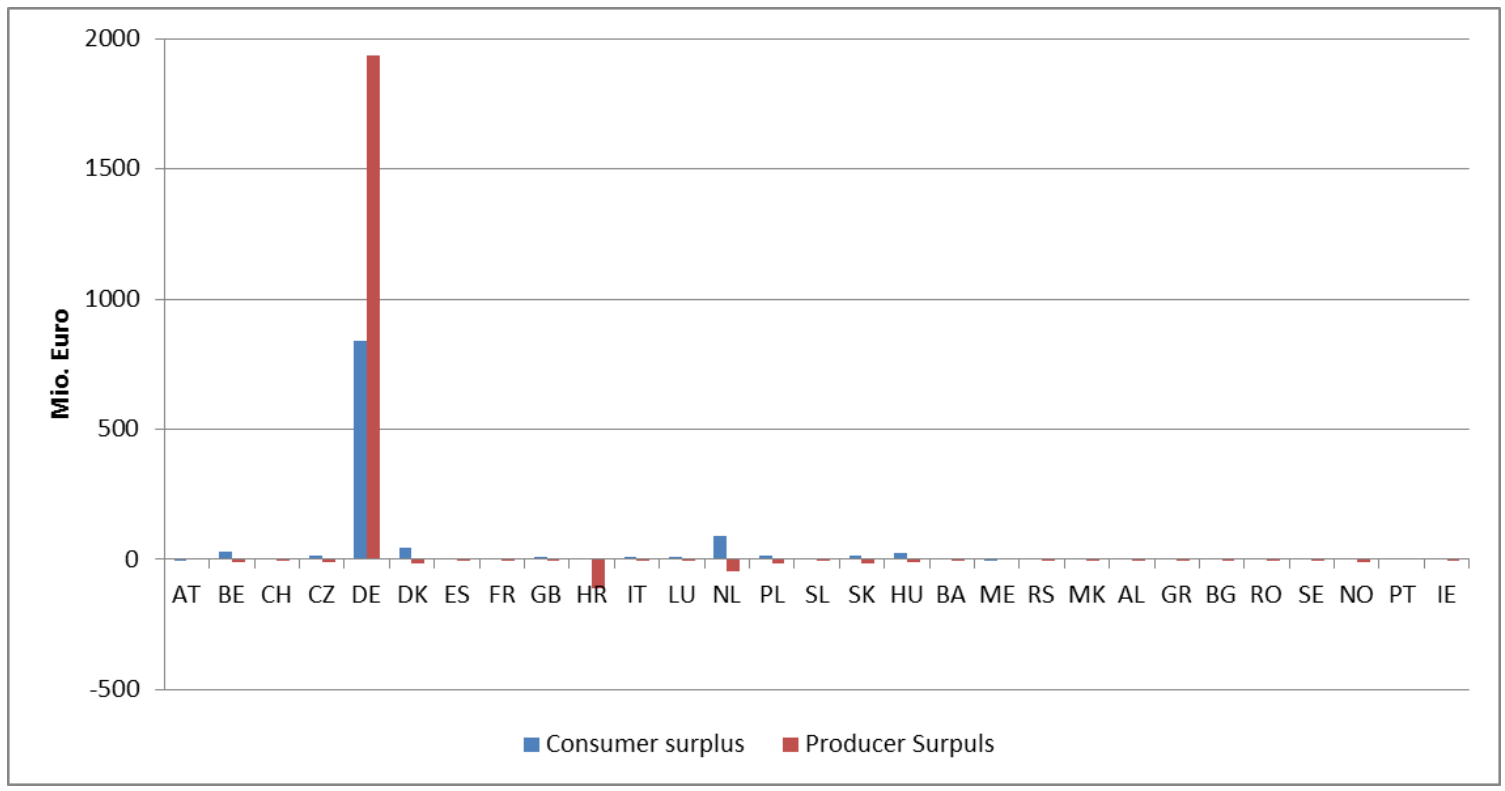

Source: Own calculations

Figure 5: Changes in Producer and Consumer Surpluses.

In consequence of reductions in the electricity prices the consumer surpluses will increase. For Germany we ascertain an increase in the consumer surplus by 840 Mio. Euro. The decreases in demand in Germany for electricity from other countries will also lower the prices outside Germany. Therefore, the deployment of CCS in Germany will affect consumer surpluses in others countries, too.

Usually it is supposed that the use of CCS techniques is linked with higher investment cost (see, e.g. IEA 2011a and ZEP 2011). Assuming that the additional producer surplus will be used completely for covering the increases of the investment cost, per kW installed CCS capacity 31 Euro/kW are gained in the CCS20, 66 Euro/kW in the CCS30 and 89 Euro/kW in the CCS40 scenario as annual contribution margin for CCS. 
Table 2: Results

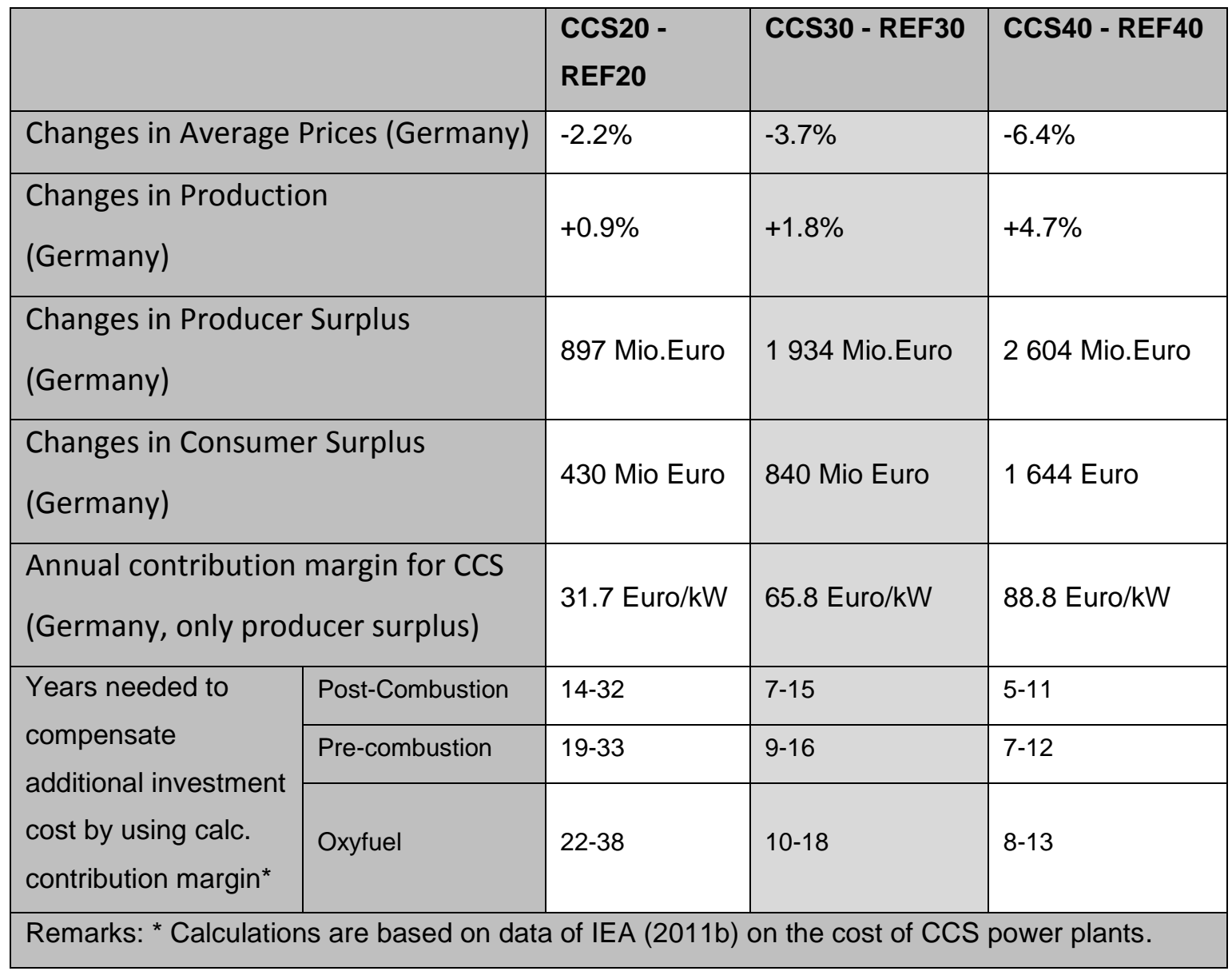

Source: Own calculations

IEK-STE 2012

The IEA estimates that the investment cost of CCS will be 500 to 1200 Euro/kW higher than the cost of coal power plants without CCS. The specific surcharge in the investment cost depends on the individual technology applied. According to the IEA, post-combustion power plants will be only 500-1000 Euro/kW costlier than conventional power plants. For oxyfuel-power plants 700 to 1200 Euro/kW will be needed in addition (IEA 2011c).

If we assume an annual contribution margin of 31.7 Euro, then up to 38 years will be necessary for compensating additional investment cost. As presented in Figure 5, with increasing $\mathrm{CO}_{2}$-prices the annual contribution margins for CCS rise. If we however assume a $\mathrm{CO}_{2}$-price of $30 \mathrm{Euro} / \mathrm{t} \mathrm{CO}_{2}$ instead of 20 Euro/t $\mathrm{CO}_{2}$, then the payback period 
would be significantly shorter. In the case of $40 \mathrm{Euro} / \mathrm{t} \mathrm{CO}_{2}$ the investors face a payback period of 'only' about 10 years.

By using 'years needed to compensate additional investment cost by using calculated contribution margin' as an indicator for the profitability of an investment in CCS, it has to be taken into account that the calculated contribution margins reflect only the time scale of one year. However, the system is dynamic and market conditions might change significantly, especially when we take a look at longer periods. Depending on changes in electricity demand, production cost and the availability of power plant techniques the margins could be higher or lower. Examples for the impact of changes in the installed REG-capacity on prices, production and producer surplus are presented in Table 3.

Table 3: Results - CCS in combination with modified Wind/PV-capacity

\begin{tabular}{|l|l|l|l|l|}
\hline & \multicolumn{2}{|c|}{ CCS30+REG } & \multicolumn{2}{c|}{ CCSred30+REG } \\
\hline Reference-Scenario & REF30 & REF30+REG & REF30 & $\begin{array}{l}\text { REF30red } \\
+ \text { REG }\end{array}$ \\
\hline $\begin{array}{l}\text { Changes in Average Prices } \\
\text { (Germany) }\end{array}$ & $-9.4 \%$ & $-5.5 \%$ & $1.2 \%$ & $-2.3 \%$ \\
\hline $\begin{array}{l}\text { Changes in Production } \\
\text { (Germany) }\end{array}$ & $5.6 \%$ & $2.7 \%$ & $-3.8 \%$ & $0.7 \%$ \\
\hline $\begin{array}{l}\text { Changes in Producer Surplus } \\
\text { (Germany) }\end{array}$ & +2281 Mio. & +1256 Mio. \\
Euro & Euro & +2403 Mio. & +1352 Mio. \\
\hline $\begin{array}{l}\text { Changes in Consumer Surplus } \\
\text { (Germany) }\end{array}$ & $\begin{array}{l}2150 \text { Mio. } \\
\text { Euro }\end{array}$ & $\begin{array}{l}1200 \text { Mio. } \\
\text { Euro }\end{array}$ & $\begin{array}{l}-280 \text { Mio. } \\
\text { Euro }\end{array}$ & $\begin{array}{l}544 \text { Mio. } \\
\text { Euro }\end{array}$ \\
\hline
\end{tabular}

Source: Own calculations IEK-STE 2012

An extension of the installed wind power capacity by $10 \mathrm{GW}$ and in the PV capacity by $20 \mathrm{GW}$ (without a reduction in the installed capacity of fossil fuels) will result in lower prices at the electricity spot market. Consequently less electricity will be produced domestically. All in all, the producer surplus will increase because the negative impact of decreasing electricity prices will be compensated by increases in the production and 
beneficial modifications in the slope of the merit-order curve. Assuming that the extension in installed wind and PV goes in line with smaller numbers of coal power plants, price changes are significantly smaller. Comparing the scenario of higher REGcapacity and lower CCS-capacity with reference scenario REF30, the average electricity price will become even higher because costly back-up capacities have to be implemented in order to avoid surplus gaps in electricity supply caused by nonavailability of wind and PV power.

In all CCS scenarios with increases in installed REG the augmentations of producer surplus will rise. If we assume that the changes in producer surplus are used for compensating higher investment cost of CCS power plants, then - with lower CCS and higher REG - the annual contribution margin for CCS will increase significantly. However, it has to be taken into account that wind and PV have low operation cost but high investment costs which also has to be compensated for somehow.

\section{Conclusions}

In many studies and also in legal documents, carbon dioxide capture and storage (CCS) is highlighted as important option to mitigate global warming. The European Parliament and the Council assess that $15 \%$ of the carbon dioxide reductions required in the EU in 2030 could be achieved by the implementation of carbon capture and storage technologies (European Parliament and Council 2009). ${ }^{7}$

Power plants equipped with CCS are more expensive than conventional power plants regarding investment cost, but with increasing prices for $\mathrm{CO}_{2}$-allowances the variable cost (including cost for fuel and $\mathrm{CO}_{2}$ allowances but not capital cost) will become lower than the respective cost of conventional power plants. Thus, due to the impact of carbon-pricing, the merit-order curve of the country using CCS is affected.

From the electricity producers' perspective, the use of CCS will bring about additional gains, as production cost will decline while the quantities of electricity sold on the

\footnotetext{
${ }^{7}$ Similarly, Golombek et al. (2011: 228) point out that "CCS is likely to become an important carbon abatement option for Europe."
} 
market will increase. The use of CCS power will also lower the whole-sale electricity prices which producers can claim, but this will not sap the additional gains for the electricity suppliers.

The increase in the producer surplus can be used to cover additional investment cost. However, high $\mathrm{CO}_{2}$ permit prices are necessary to reach acceptable pay-back periods. Increases in the installed REG-capacity can have positive and negative impacts of the use of CCS. If enough 'cheap' capacity is available and there is no need to use costly backup capacities, electricity prices will decline. With lower electricity prices the electricity imports will be reduced and the export will rise, respectively. In total the producer surplus will be higher than without extension of REG. If the increase in REG capacities goes along with reductions in coal power plant capacities, electricity prices will increase and the production will decline. However, the producer surplus will remain positive.

Also from the perspective of electricity consumers in Germany, the use of CCS is beneficial as electricity prices will be lowered in comparison to a scenario without CCS. In the face of the current intense discussion about the burdens of the European energy systems' transformation on electricity consumers (see, e.g., Gelabert, Labandeira and Linares 2011; Kirat and Ahamada 2011; Nestle 2012), this seems to be a strong argument in favor of pursuing the CCS option, too. 


\section{References}

Azar, C., Lindgren, K., Larson, E. and Möllersten, K., 2006. Carbon Capture and Storage from Fossil Fuels and Biomass - Costs and Potential Role in Stabilizing the Atmosphere, Climatic Change, 74, 47-79.

Edenhofer, O., Knopf, B., Luderer, G., Steckel, J. and Bruckner, T., 2011. More Heat Than Light? On the Economics of Decarbonisation, in: Sustainable Energy, K.D. John and D.T.G. Rübbelke (eds.), Routledge, Abingdon, New York, 70-108.

EEX, 2011a): Actual Solar Power Generation, http://www.transparency.eex.com, 11/12/2011.

EEX, 2011b. Actual Wind Power Generation, http://www.transparency.eex.com, 11/12/2011.

ENTSO-E, 2011a. Data Portal CE - Production, http://www.entsoe.eu, December 2011.

ENTSO-E, 2011b. NTC Values, https://www.entsoe.eu/resources/ntc-values/ntc-matrix, 02/03/2011.

ENTSO-E, 2011c. Consumption Data, https://www.entsoe.eu/resources/dataportal/consumption, 02/03/2011.

EURELECTRIC, 2010. Power Statistics 2010 Edition, Brussels.

European Parliament and Council, 2009. Directive 2009/31/EC of the European Parliament and of the Council of 23 April 2009 on the geological storage of carbon dioxide and amending Council Directive 85/337/EEC, European Parliament and Council Directives 2000/60/EC, 2001/80/EC, 2004/35/EC, 2006/12/EC, 2008/1/EC and Regulation (EC) No 1013/2006, Strasbourg.

Gelabert, L., Labandeira, X. and Linares, P., 2011. An Ex-post Analysis of the Effect of Renewables and Cogeneration on Spanish Electricity Prices, Energy Economics, 33, S59-S65.

Golombek, R., Greaker, M., Kittelsen, S.A.C., Røgeberg, O. and Aune, F.R., 2011. Carbon Capture and Storage Technologies in the European Power Market, Energy Journal, 32, 209-237.

Hake, J.-F., Höwener, H., Schenk, O. and Seier, J., 2009. CCS for Germany: Policy, R\&D and Demonstration Activities, Energy Procedia, 1, 3917-3925.

Haszeldine, R.S., 2009. Carbon Capture and Storage: How Green Can Black Be?, Science, 325, 1647-1652.

Hoel, M. and Jensen, S., 2010. Cutting Costs of Catching Carbon: Intertemporal Effects under Imperfect Climate Policy, Discussion Paper No. 639, Statistics Norway, Research Department, Oslo.

House, K.Z., Harvey, C.F., Aziz, M.J. and Schrag, D.P., 2009. The Energy Penalty of Postcombustion $\mathrm{CO}_{2}$ Capture \& Storage and Its Implications for Retrofitting the U.S. Installed Base, Energy \& Environmental Science, 2, 193-205.

IEA, 2009. Technology Roadmap - Carbon Capture and Storage, OECD/IEA, Paris.

IEA, 2011a. Cost and Performance of Carbon Dioxide Capture from Power Generation, OECD/IEA, Paris.

IEA, 2011b. World Energy Outlook 2011, OECD/IEA, Paris.

IEA, 2011c. World Energy Outlook- Investment Costs.

http://www.worldenergyoutlook.org/investments.asp, 07/02/2012. 
IPCC, 2005. Carbon Dioxide Capture and Storage, B. Metz, O. Davidson, H. de Coninck, M. Loos and L. Meyer (eds.), Cambridge University Press, Cambridge.

Kirat, D. and Ahamada, I., 2011. The Impact of the European Union Emission Trading Scheme on the Electricity-generation Sector, Energy Economics, 33, 995-1003.

Lüken, M., Edenhofer, O., Knopf, B., Leimbach, M., Luderer, G. and Bauer, N., 2011. The Role of Technological Availability for the Distributive Impacts of Climate Change Mitigation Policy, Energy Policy, 39, 6030-6039.

Nestle, U., 2012. Does the Use of Nuclear Power Lead to Lower Electricity Prices? An Analysis of the Debate in Germany with an International Perspective, Energy Policy, 41, 152-160.

Oltra, C., Sala, R., Solà, R., Di Masso, M. and Rowe, G., 2010. Lay Perceptions of Carbon Capture and Storage Technology, International Journal of Greenhouse Gas Control, 4, 698-706.

Praetorius, B. and Schumacher, K., 2009. Greenhouse Gas Mitigation In a Carbon Constrained World: The Role of Carbon Capture and Storage, Energy Policy, 37, 5081-5093.

Ricci, O., 2012. Providing Adequate Economic Incentives for Bioenergies with $\mathrm{CO}_{2}$ Carbon Capture and Geological Storage, Energy Policy, 44, 362-373.

Schaber, K., Steinke, F. and Hamacher, T., 2012. Transmission Grid Extensions for the Integration of Variable Renewable Energies in Europe: Who Benefits Where? Energy Policy, 43, 123-135.

Sensfuß, F., Ragwitz, M. and Genoese, M., 2008. The Merit-order Effect: A Detailed Analysis of the Price Effect of Renewable Electricity Generation on Spot Market Prices in Germany, Energy Policy, 36, 3086-3094.

Shackley, S., Waterman, H., Godfroij, P., Reiner, D., Anderson, J., Draxlbauer, K. and Flach, T., 2007. Stakeholder Perceptions of $\mathrm{CO}_{2}$ Capture and Storage in Europe: Results from a Survey, Energy Policy, 35, 5091-5108.

Stauffer, P.H., Keating, G.N., Middleton, R.S., Viswanathan, H.S., Berchtold, K.A., Singh, R.P., Pawar, R.J. and Mancino, A., 2011. Greening Coal: Breakthroughs and Challenges in Carbon Capture and Storage, Environmental Science \& Technology, 45, 8597-8604.

Viebahn, P., Nitsch, J., Fischedick, M., Esken, A., Schüwer, D., Supersberger, N., Zuberbühler, U. and Edenhofer, O., 2007. Comparison of Carbon Capture and Storage with Renewable Energy Technologies Regarding Structural, Economic, and Ecological Aspects in Germany, International Journal of Greenhouse Gas Control, 1, 121-133.

ZEP, 2011. The Costs of $\mathrm{CO}_{2}$ Capture, ZERO EMISSIONS PLATFORM, Brussels. 


\section{BC3 WORKING PAPER SERIES}

\section{Basque Centre for Climate Change (BC3), Bilbao, Spain}

The BC3 Working Paper Series is available on the internet at the following addresses:

http://www.bc3research.org/lits_publications.html

$\underline{\text { http://ideas.repec.org/s/bcc/wpaper.html }}$

BC3 Working Papers available:

2011-05 Wan-Jung Chou, Andrea Bigano, Alistair Hunt, Stephane La Branche, Anil Markandya, Roberta Pierfederici: Households' WTP for the Reliability of Gas Supply

2011-06 Roger Fouquet and Peter J.G. Pearson: The Long Run Demand for Lighting: Elasticities and Rebound Effects in Different Phases of Economic Development

2011-07 Ibon Galarraga, David Heres Del Valle and Mikel González-Eguino: Price Premium for High-Efficiency Refrigerators and Calculation of Price-Elasticities for Close-Substitutes: Combining Hedonic Pricing and Demand Systems

2011-08 Anil Markandya, Mikel González-Eguino, Patrick Criqui, Silvana Mima: Low Climate Stabilisation under Diverse Growth and Convergence Scenarios

2011-09 Martin Altemeyer-Bartscher, Anil Markandya and Dirk Rübbelke: The Private Provision of International Impure Public Goods: the Case of Climate Policy

2011-10 Aline Chiabai, Ibon Galarraga, Anil Markandya and Unai Pascual: The Equivalency Principle for Discounting the Value of Natural Assets: An Application to an Investment Project in the Basque Coast

2011-11 Roger Fouquet: The Demand for Environmental Quality in Driving Transitions to Low Polluting Energy Sources

2011-12 Joseph V. Spadaro: The Uniform World Model: A Methodology for Predicting the Health Impacts of Air Pollution

2011-13 Thomas Heyd: Climate Change, Responsibilities, and Defeatism and Complacency

2012-01 Roger Fouquet: Trends in Income and Price Elasticities of Transport Demand (18502010)

2012-02 Sébastien Foudi: Exploitation of soil biota ecosystem services in agriculture: a bioeconomic approach

2012-03 Mikel González-Eguino, Anil Markandya and Marta Escapa: From shadow to green: Linking environmental fiscal reform and the informal economy

2012-04 Anil Markandya, Mikel González-Eguino and Marta Escapa: Environmental fiscal reform and unemployment in Spain

2012-05 Dirk Rübbelke and Stefan Vögele: Effects of Carbon Dioxide Capture and Storage in Germany on European Electricity Exchange and Welfare 